\title{
Are there gender differences in instrumental music practice?
}

Susan Hallam, Maria Varvarigou, Andrea Creech, Ioulia Papageorgi, Teresa Gomes, Jennifer Lanipekun and Tiija Rinta.

\begin{abstract}
This research aimed to consider whether there were gender differences in the amount of practice undertaken by boys and girls, the practice strategies adopted and motivation to practice. 2027 girls and 1225 boys aged 6-19 years, ranging in level of expertise from beginner through to conservatoire entrance level, playing instruments representative of the classical and popular instruments played in the UK completed a self-report Likert scale questionnaire. There were no statistically significant gender differences in weekly practice time or motivation to practice. Factor analysis of statements relating to practice revealed seven factors. There were statistically significant gender differences in relation to the adoption of systematic practice strategies (girls were more systematic), concentration (boys perceived they had higher levels of concentration ) and immediate correction of errors (girls reported more immediate correction). There were no statistically significant gender differences in relation to the organisation of practice, the use of recordings and a metronome, the use of analytic strategies, and the adoption of ineffective practice strategies although for this factor there was a statistically significant interaction between gender and level of expertise.
\end{abstract}

Key words: Music, practice, instrumental practice, gender, attitudes

\section{Are there gender differences in instrumental music practice?}


This paper presents a reanalysis of a factor analytic study which addressed issues relating to changes in individual practice in young people as they developed instrumental expertise (Hallam et al., 2012). The current paper reanalyses the data to enable comparisons to be made of the practising strategies adopted by boys and girls. The earlier paper was based on data from 3,325 children ranging in level of expertise from beginner through to grade 8 level (the minimum required for conservatoire entrance in the UK). Participants completed a questionnaire which consisted of a number of statements relating to practising strategies, organization of practice, concentration and attitudes towards practising using a seven-point Likert rating scale. Data were analyzed in relation to nine levels of expertise. Factor analysis revealed seven factors relating to practice itself: the adoption of systematic practice strategies; the organization of practice; the use of recordings for listening and feedback and use of the metronome; the use of analytic strategies; the adoption of ineffective strategies; concentration; and the immediate correction of errors. There were statistically significant linear relationships between grade level and the adoption of systematic practice strategies; use of recordings for listening and feedback and use of the metronome; the adoption of ineffective strategies; and immediate correction of errors but not for organization of practice; use of analytic strategies; and concentration. The data on attitudes towards practice showed that students enjoyed practice less the more advanced they became. The research reported here extends that research exploring gender differences in approaches to practising.

There is a long history of research on practice. Two main strands have emerged, one focusing on the amount of time spent practising, the other on the quality of practice. This research has demonstrated the key role of accumulated practice in determining the level of musical expertise attained, although there are substantial individual differences (e.g. Ericsson, Krampe \& Tesch-Romer, 1993; Hallam, 1998; Hallam et al., 2012; Jørgensen, 2002; Platz, Kopiez, Lehmann \& Wolf, 2014; Sloboda, Davidson, Howe \& Moore, 1996) and the 
importance of the quality of practice with strategy use changing as expertise develops (e.g. Chaffin, Imreh, Lemieux \& Chen, 2003; Duke, Simmons \& Cash, 2009; Gruson, 1988; Hallam, 1997; Hallam et al., 2012, McPherson \& Renwick, 2001). Research on the quality of practice has considered the strategies adopted, the organisation of practice, concentration, self-regulation, meta-cognition and the development of aural schemata. For full reviews of the research on practice see (Hallam et al., 2012) and Jørgensen and Hallam (2016). Surprisingly, no research to date has focused on the ways in which boys and girls may differ in their approach to individual instrumental practice. This paper addresses that issue.

\section{Research on gender differences in music education}

Boys are underrepresented in those learning to play an instrument (see for instance ABRSM, 1994; Green, 1997; Hanley, 1998). Girls also tend to perform better in school music examinations (JCQ, 2014; Keiper et al., 2009) despite there being no consistent gender differences in measured musical ability (Gordon, 1986), or teachers' ratings of musical ability (Hallam, 2004). Music tends to be regarded as a feminine subject (Green 1997; Hargreaves, Comber \& Colley, 1995), although boys playing instruments tend to report higher levels of enjoyment of music than girls (Hallam, 2013). Boys tend to demonstrate more interest in music when it is linked to technology and report more positive attitudes towards and confidence in using music technology than girls (Comber, Hargreaves \& Colley, 1993; Green, 1997; Hanley, 1998). Research on school music suggests that girls value music more than boys and perceive that they have higher competence levels (McPherson \& O’Neill, 2010), although, overall, findings on gender differences in musical self-efficacy are mixed depending on the context (Hendricks, 2014; Nielsen, 2004; Ritchie \& Williamon, 2011a; 2011b; Welch et al., 2008; Wehr-Flowers, 2006). There are also gender differences in attributions of success with female students generally rating statements related to effort higher than males (Schatt, 2011). 
There continue to be differences in the instruments that are played by boys and girls with girls tending to play the smaller higher pitched instruments (Abeles, 2009; Abeles \& Porter, 1978; Cramer, Million, \& Perreault, 2002; Hallam, Rogers \& Creech, 2008; Harrison, 2000; Killian \& Satrom, 2011; Sheldon \& Price, 2005; Wych, 2012), although girls tend to select a wider variety of instruments which they would like to play along the feminine - masculine continuum than boys, particularly at primary school (Zervoudakes \& Tanur, 1994). This stereotyping extends to world music instruments (Kelly \& Van Weelden, 2014) and is evident in very young children (Marshall \& Shibazaki, 2012). However, for less gender stereotyped instruments the musical style and the performance context play a part. Instrument choice to some extent is linked to genre with girls being under-represented in some popular music areas (Baker \& Cohen, 2008).

There are some identified differences in the ways that boys and girls approach musical tasks. When composing in groups boys tend to combine musical gestures and non-verbal communication while girls separate these (Abramo, 2011). In music lessons girls tend to adopt a more compliant style with the boys adopting a more serious style (Zhukov, 2007), while male teachers adopt a more analytic approach, females more balanced. The lessons of female students tend to focus more on expression, those of males on structure (Zhukov, 2008). In higher education male students have been found to adopt higher levels of critical thinking (Nielsen, 2004), while female students tend to appreciate the benefits of attending master classes valuing the opportunity to hear others and their interpretations (Long, Hallam, Creech, Gaunt \& Robertson, 2012). Girls are also more influenced in their attitudes towards practice by their teachers and parents whereas boys are more influenced by their friends (Hallam, 2004), although there is some evidence that boys playing classical instruments 
perceive greater parental support than girls (Hallam, 2013). Despite this body of research on gender differences we know little about the ways in which boys and girls may differ in their approach to individual instrumental practice. The research reported here aims to address that issue comparing the nature and amount of practice undertaken by boys and girls and whether there are any interactions with level of expertise.

The specific research questions were:

Are there gender differences in the frequency and amount of practice?

Are there gender differences in practising strategies, levels of concentration and the organisation of practice?

Are there gender differences in attitudes towards practising?

If there are gender differences in the above do they interact with level of expertise?

\section{Method}

\section{Particpants}

A total of 3325 children ranging in level of expertise from beginner through to Grade 8 level (minimum required for conservatoire entrance in the UK) completed questionnaires. The age range was from 6 to 19 years. The instruments that they played were representative of the classical and popular instruments played in the UK (for further details see Hallam et al., 2012). 2027 (61\%) of the sample were girls; 1225 (37\%) were boys, a total for the reanalysis of 3252 as some students did not indicate their gender. The male participants were on average slightly older with a mean age of 13.3 years $(S D=2.8)$ while the average female age was 12.9 years $(S D=2.8)$. These differences were statistically significant $(F(1,3211)=17.74$, $p=.0001)$. There were also differences in the number of months learning with the boys on average having been learning a little longer $(M=60.8, S D=37.2)$ than the girls $(M=58.23$, $S D=37.7)$. These differences were not statistically significant. There were no statistically 
significant gender differences in relation to the average most recent grade examination taken (boys $M=4.0$, girls $M=3.9$ ) or the pass level at which the last grade was attained (boys $M=$ 1.59 , girls $M=1.62$ ).

\section{Materials}

A self-report questionnaire was used as a means of collecting data. The students were asked to indicate their gender in terms of male/female. While acknowledging the multiple forms that gender can take it was decided that the addition of further choices might be confusing for the younger participants. The questionnaire was identical to that used in the earlier study (Hallam et al., 2012) and sought information about the level of expertise attained as assessed by the highest examination grade achieved in graded independent instrumental examinations from preliminary to Grade 8 . Respondents were also asked to indicate the number and length of practice sessions in a typical week and respond on a seven point Likert scale (seven indicating the strongest agreement) to a series of statements relating to: the practising strategies adopted; the organization and management of practice; and motivation to practise. The Cronbach's Alpha for the questionnaire items included in the analysis was .78. The full questionnaire is included in the appendix and indicates which statements relate to each element of the analysis.

\section{Procedure}

The research was designed taking account of the ethical guidelines of the British Psychological Society and the British Educational Research Association and was approved by the ethics committee of the Institute of Education, University of London. Details of the procedures adopted can be found in Hallam et al. (2012). 


\section{Results}

\section{Gender differences in the frequency and amount of practice}

The boys reported practising slightly more days each week than the girls (boys $M=4.7$; girls $M=4.5$ days $)$. This difference was statistically significant $(t(3219)=2.26, \mathrm{p}=.025)$. The boys also reported practising for slightly longer on each day (boys $M=43$ minutes; girls $M=$ 41 minutes). This difference was not statistically significant. Combining these two data sources led to the boys on average reporting 230 minutes of weekly practice as opposed to 209 minutes for the girls. This difference was not statistically significant. There was also no significant interaction between gender and level of expertise although there were statistically significant differences in the amount of weekly practice by level of expertise $(F(8,2795)=$ $48.52, \mathrm{p}=.0001$, np $2=.123)($ see Figure 1$)$.

Figure 1: Average weekly practice in minutes by level of expertise and gender

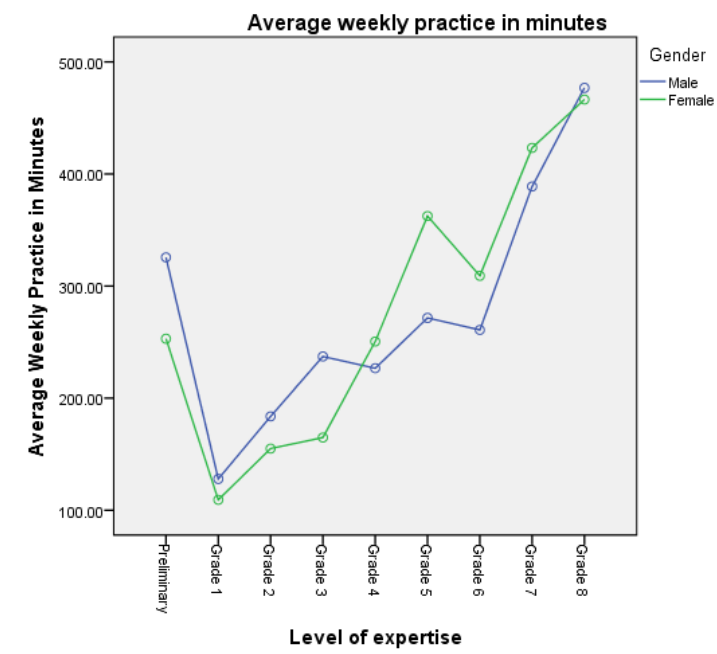

Are there gender differences in practising strategies, levels of concentration and the organisation of practice? Do any gender differences interact with level of expertise?

To explore the relationships between the practice variables, factor analysis was undertaken. A Principal components analysis was undertaken as it provides an empirical analysis of the data 
set (Tabachnick \& Fidell, 2001) followed by a varimax rotation (Green et al., 2000;

Tabachnick \& Fidell, 2001). Eigenvalues were retained if they were greater than 1 and the scree plot was used to support the identification of the number of factors. A Kaiser-MeyerOlkin (KMO) test and an anti-matrix of covariances and correlations were used to check sampling adequacy. The latter showed that all elements on the diagonal of these matrices were greater than -.5 , the necessary requirement. The KMO was 0.86 , greater than the 0.5 required to assess the adequacy of the sample (Field, 2000). Following these procedures a seven factor solution was deemed to be the most appropriate. Full details of the factor analysis are provided in Hallam et al. (2012). Multivariate analysis of variance taking account of gender and level of expertise in relation to the factors showed highly significant outcomes for gender $(F(7,2421)=7.85, \mathrm{p}=.0001, \mathrm{np} 2=.021)$, for level of expertise $(F$ $(56,16989)=14.5, \mathrm{p}=.0001, \mathrm{np} 2=.052)$ and for the interaction between gender and level of expertise $(F(56,16989)=1.53, \mathrm{p}=.007, \mathrm{np} 2=.005)$. Post hoc analysis focused on linear trends relating to the development of expertise rather than differences occurring at specific levels of expertise.

\section{Factor 1: Adoption of systematic practice strategies}

Factor 1 had an eigenvalue of 2.9 accounting for $10.7 \%$ of the variance. This factor had high weightings for practising sections slowly when having made a mistake (.737); practising difficult sections over and over again (.68); slow practice (.649); gradually speeding up when learning fast passages (.585); recognising errors (.558); marking things on the part (.308); and practising small sections (.404). There was a significant effect of level of expertise on Factor $1(F(4,2492)=4.09, p=.0001$, nр $2=.011)$ with a statistically significant linear trend $(F(1$, $2492)=6.79, p=.01)($ see Figure 2$)$ indicating that as the level of expertise increased the adoption of systematic practice strategies increased. There was a statistically significant 
gender difference in relation to the use of systematic practice strategies $(F(1,3045)=23.28, \mathrm{p}$ $=.0001$, np $2=.01)$. The girls were more likely to adopt systematic practice strategies $(M=$ $.069)$ as opposed to the boys $(M=-.069)$. The negative score for the boys on this factor reflects the fact that the mean for each factor is 0 . There was no statistically significant interaction between gender and level of expertise (see Figure 3). A multivariate analysis of variance on the statements which had high weightings on Factor 1 as outlined above was highly significant $(F(8,3050)=16.14, \mathrm{p}=.0001)$. The items within that analysis which indicated statistically significant gender differences related to the statements 'I practice things slowly' $(F(1,3050)=13.8 . \mathrm{p}=.0001$, np $2=.005)($ boys $M=4.76, S D=1.4$; girls $M=$ 4.95, $S D=1.3$ ); 'When I make a mistake I practice the section where I went wrong slowly' $(F(1,3050)=36.7, \mathrm{p}=.0001, \mathrm{np} 2=.001)($ boys $M=5.31, S D=1.3, \operatorname{girls} M=5.6, S D=1.2$ ); 'When something is difficult I play it over and over again' $(F(1,3050)=8.87, \mathrm{p}=.003, \mathrm{np}$ $2=.003$ ) (boys $M=5.47, S D=1.2$, girls $M=5.6, S D=1.2$, 'I learn by playing slowly to start with and then gradually speed up' $(F(1,3050)=78.4, \mathrm{p}=.0001, \mathrm{np} 2=.012)$ (boys $M$ $=4.76, \mathrm{SD}=1.5$, girls $M=5.11, \mathrm{SD}=1.4$ ); and 'When I am practising I mark things on the part to help me' $(F(1,3050)=71.19, \mathrm{p}=.0001$, np $2=.023)($ boys $M=4.33, S D=1.7$, girls $M$ $=4.87, S D=1.6$ ). 
Figure 2: Adoption of systematic practice strategies by gender and level of expertise

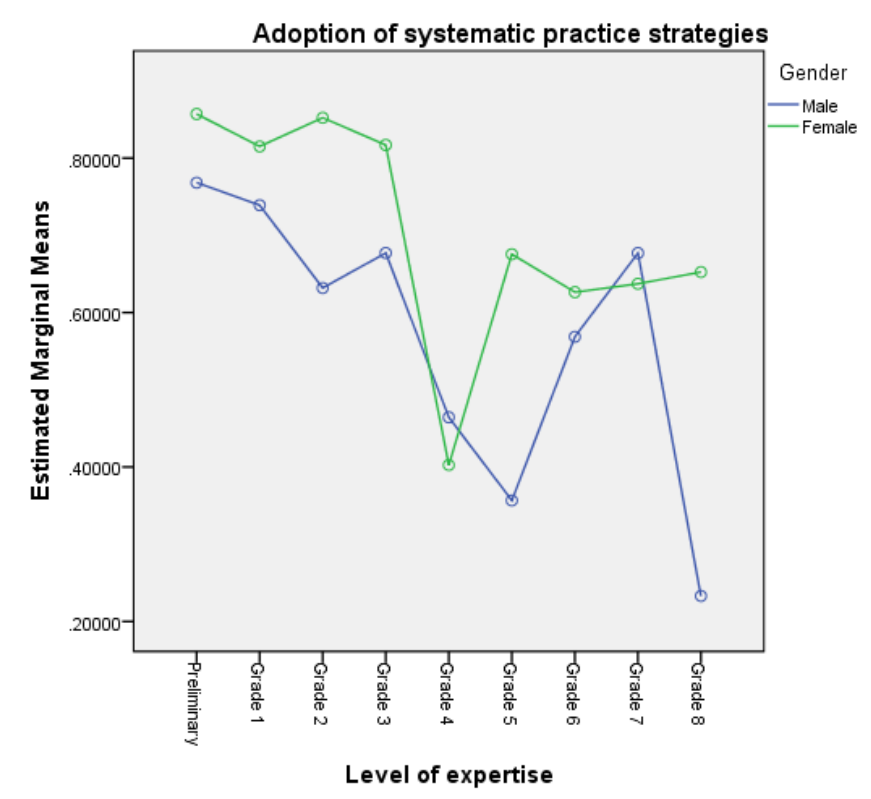

\section{Factor 2: Organisation of practice}

Factor 2 had an eigenvalue of 2.073 accounting for $7.7 \%$ of the variance. This factor related to the organisation of practice including starting practice with scales (.734); making a list of what had to be practised (.621); starting with warm up exercises (.546); starting with studies (.444); setting targets to achieve in each practice session (.381); and marking things on the part (.302). There was a significant effect of level of expertise on Factor $2(F=(8,2492) 4.92$, $p=.0001$, nр $2=.016$ ) but no statistically significant linear trend indicating that as level of expertise increased there was no systematic increase in the organisation of practice. At the factor level there was no statistically significant gender difference and no interaction between gender and level of expertise (see Figure 3), although a multivariate analysis of variance of the five statements with high weightings on the factor was statistically significant $(F(5,3137)$ $=18.7, \mathrm{p}=.0001)$. The analysis of individual items within the multivariate analysis showed statistically significant differences in relation to the setting of targets $(F(1,3137)=5.03, \mathrm{p}=$.25, np $2=.002$ ) (boys $M=3.99, S D=1.6$, girls $M=4.14 . S D=1.5$ ); making a list of what had to be practised $(F(1,3137)=28.87, \mathrm{p}=002$, np $2=.003)($ boys $M=3.33, S D=1.7$, girls 
$M=3.53, S D=1.7)$; doing warm up exercises $(F(1,3137)=4.23, \mathrm{p}=.039$, пр $2=.001)$ (boys $M=4.77, S D=1.8$, girls $M=4.63, S D=1.7)$; starting practice with scales $(F(1,3137)$ $=13.13, \mathrm{p}-.039, \mathrm{np} 2=.001$ ) (boys $M=3.99, S D=1.8$, girls $M=4.12 S D=1.7$ ); and marking things on the part $(F(1,3137)=71.5, \mathrm{p}=0001, \mathrm{np} 2=.022)($ boys $M=4.37, S D=$ 1.7, girls $M=4.89, S D=1.6)$.

Figure 3: Organisation of practice by gender and level of expertise

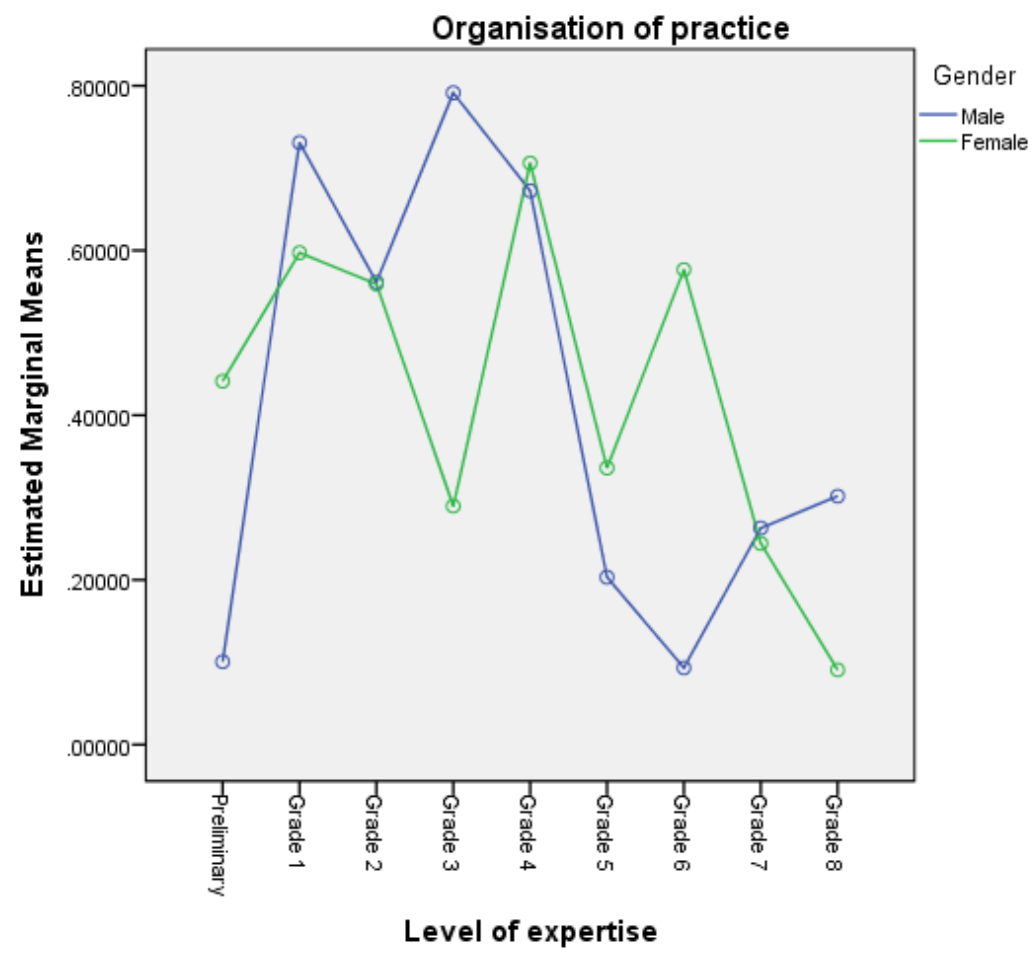

Factor 3: Use of recordings for listening and feedback and use of metronome

Factor 3 had an eigenvalue of 2.048 accounting for $7.6 \%$ of the variance. It had high weightings for recording self playing and listening to the recording (.738); listening to other recordings of the piece to be learnt (.671); and practising with the metronome (.639). There was a significant effect of level of expertise on Factor $3(F=(8,2492) 29.48, \mathrm{p}=.0001, \eta p 2$ $=.086)$ and a highly statistically significant linear trend $(F(1,2492)=184.5, p<.0001)($ see 
Figure 4). There were no statistically significant gender differences or interactions between gender and level of expertise (see Figure 4). Mulitvariate analysis of variance of the items with high loadings on the factor confirmed this.

\section{Figure 4: Use of recordings and a metronome by gender and level of expertise}

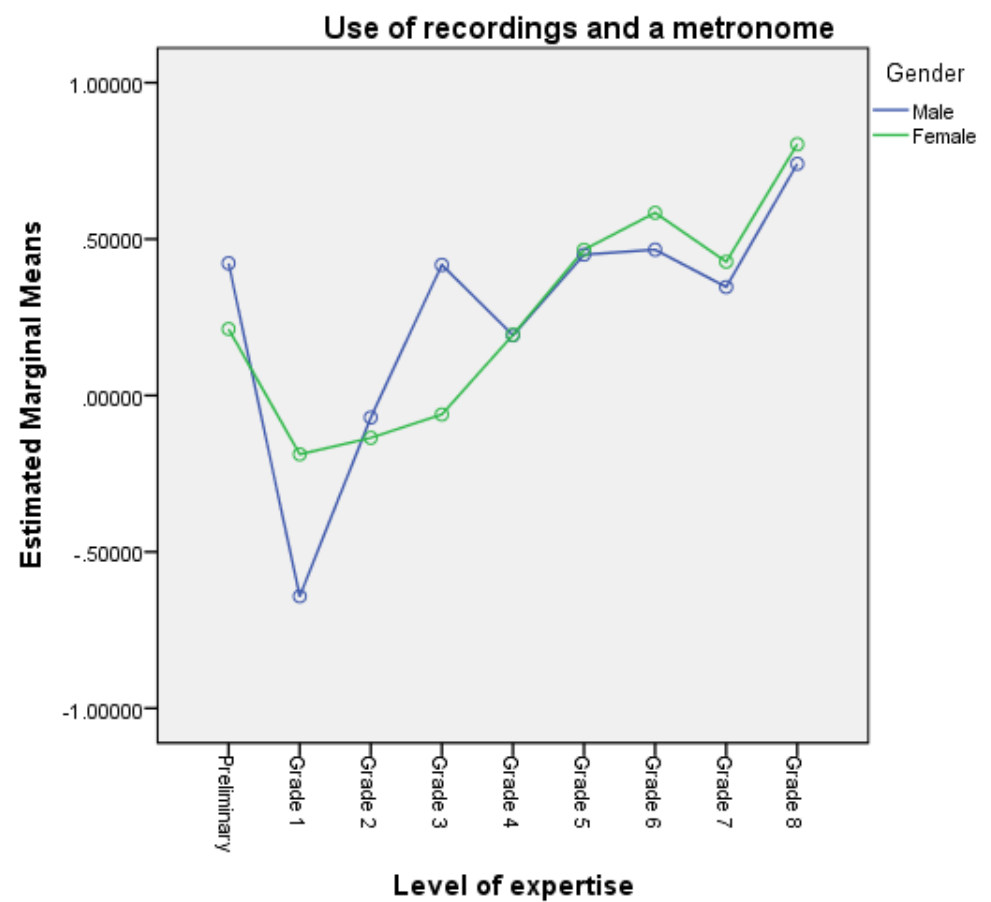

\section{Factor 4: Use of analytic strategies}

Factor 4 had an eigenvalue of 1.98 accounting for $7.3 \%$ of the variance. The factor had high weightings for: trying to find out what a piece sounds like before trying to play it (.759); getting an overall idea of a piece before practising it (.663); identifying difficult sections (.516); analysing the structure of a piece before playing it (.427); thinking about interpretation (.324); and working things out just by looking at the music and not playing (.318). There was a significant effect of level of expertise on Factor $4(F(8,2492)=3.249, p$ $=.001, n p 2=.01)$ but no statistically significant linear trend, no statistically significant 
gender differences or interactions between gender and level of expertise (see Figure 5).

Multivariate analysis of variance confirmed this.

Figure 5: Use of analytical strategies by gender and level of expertise

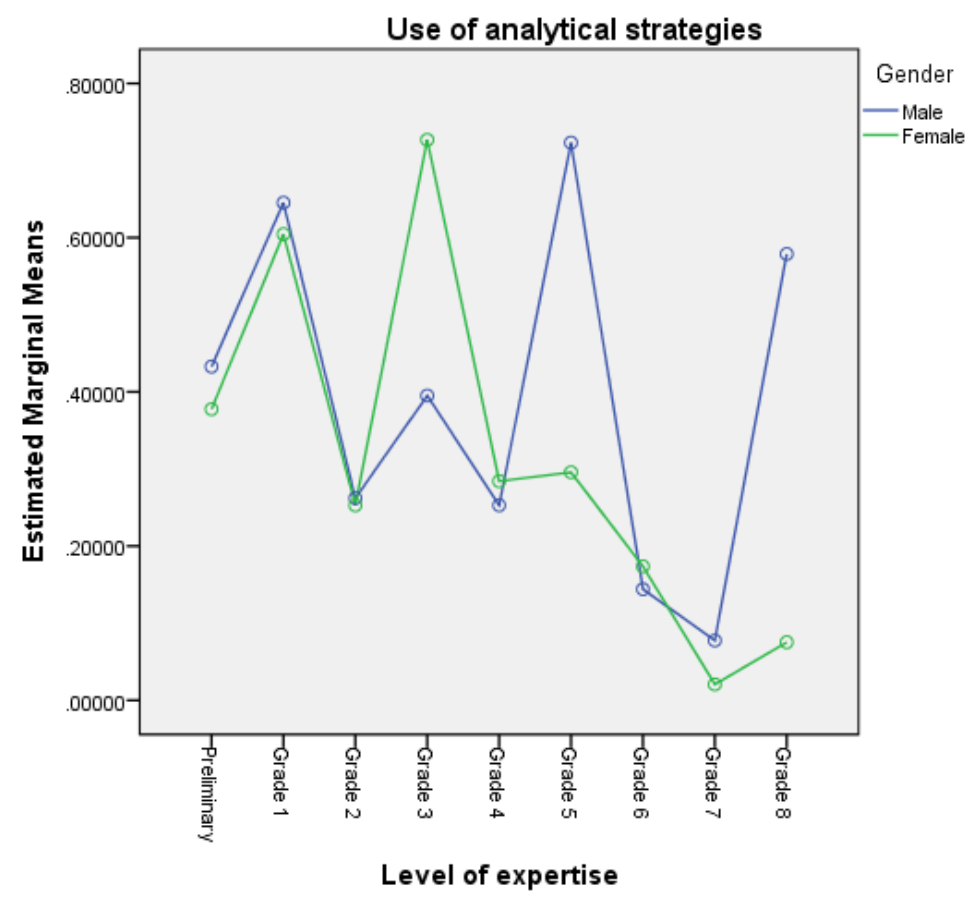

\section{Factor 5: Adoption of ineffective practising strategies}

Factor 5 had an eigenvalue of 1.87 accounting for $6.9 \%$ of the variance. There were high loadings on only playing pieces from beginning to end without stopping when practising (.7); and going back to the beginning and starting again when making a mistake (.644). There was a smaller loading on working things out just by looking at the music and not playing (.451). This latter might be conceptualised as a useful strategy, for instance, in terms of mental rehearsal. However, in previous research (Hallam, 2001b) it was consistently adopted by beginners who also tended to repeat the whole piece with no identification of difficult passages returning to the beginning of a piece when a mistake was made. For this reason the 
factor was conceptualised as referring to ineffective practising strategies. This is supported by the negative loadings on identifying difficult sections (-.222); thinking about interpretation (-266); marking things on the part (-302); and practising small sections (-.403). There was a significant effect of expertise on Factor $5(F(8,2492)=75.72, p=.0001, n p 2=.196)$ and a highly statistically significant linear trend $(F(1,2492)=462.3, p=.0001)$. Although there were no statistically significant gender differences in relation to the factor itself there was a statistically significant interaction between gender and level of expertise $(F=(1,8) 2.39+$ .015) (see Figure 6). A multivariate analysis of the items within the factor elucidated this ( $F$ $(3,3149)=7.46, \mathrm{p}=.001)$. Within the multivariate analysis there was a statistically significant gender difference in relation the statement 'When I make a mistake I go back to the beginning of the piece and start again' $(F(1,3149)=17.7, \mathrm{p}=.001, \mathrm{np} 2=.006)$ (boys $M$ $=3.36, S D=1.7$, girls $M=3.57, S D=1.6)$.

Figure 6: Use of ineffective practising strategies by gender and level of expertise

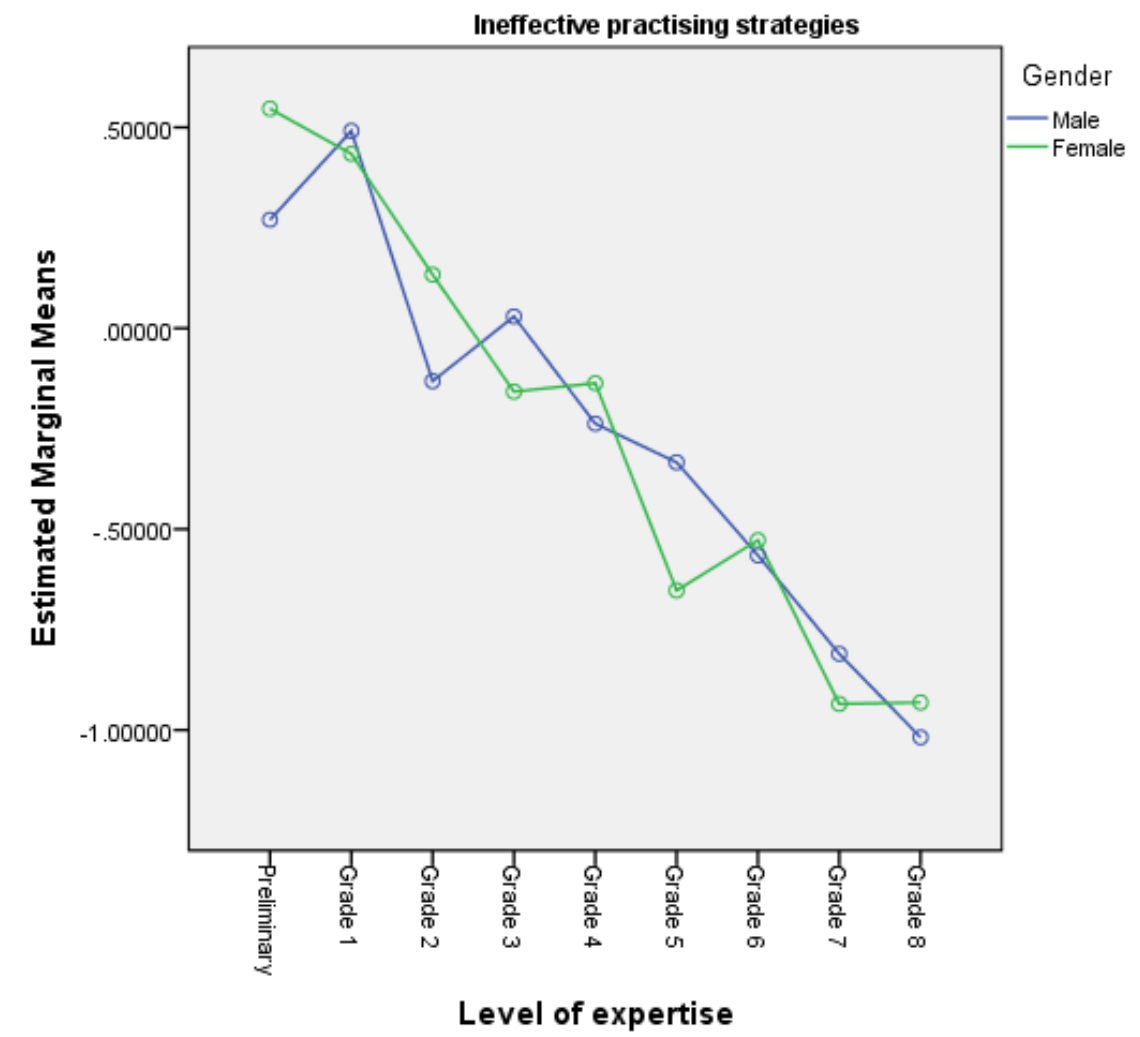




\section{Factor 6: Concentration}

Factor 6 had an eigenvalue of 1.48 accounting for $5.5 \%$ of the variance. The factor had high weightings on finding it easy to concentrate (.699) and negatively on being easily distracted when practising (-.773). There was a significant effect of level of expertise on Factor 6 ( $F$ $(8,2492)=3.218, p=.001, n p 2=.01)$ but no significant linear trend. There was a statistically significant gender difference in perceived concentration with the males perceiving that they concentrated better (boys $M=.095$, girls $M=-.051)(F(1,8)=9.059 . \mathrm{p}=.003$, np $2=.004)$ but no statistically significant interaction between gender and level of expertise (see Figure 7). Multivariate analysis revealed no statistically significant gender differences for the two individual statements.

Figure 7: Perceived levels of concentration by gender and level of expertise

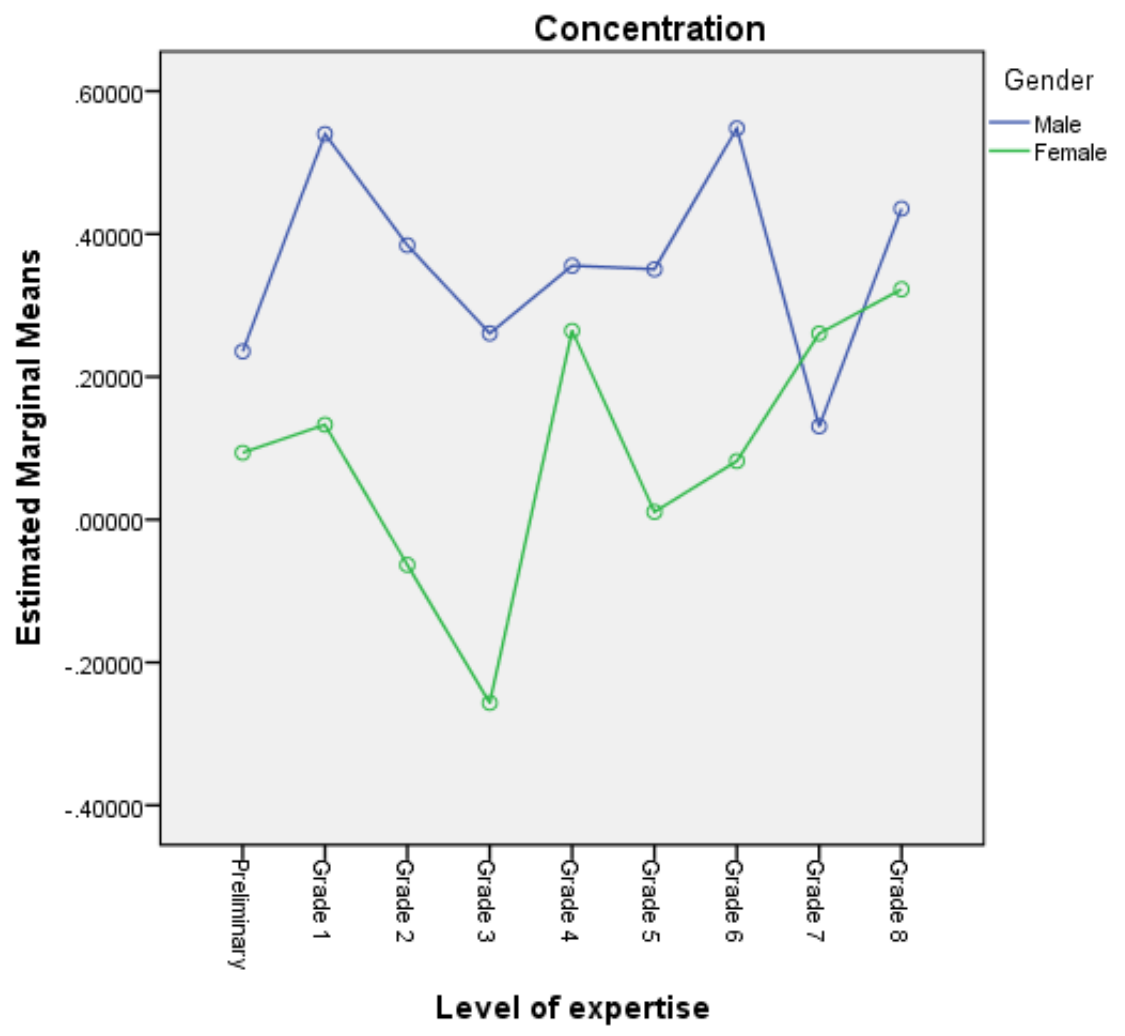




\section{Factor 7: Immediate correction of errors}

Factor 7 had an eigenvalue of 1.34 accounting for $5.0 \%$ of the variance and high weightings in relation to 'When making a mistake the wrong note is corrected and then I carry on' (.705); 'When I make a mistake I carry on without correcting it' (-.795). There was a statistically significant effect of level of expertise on Factor $7(F(8,2492)=2.54, p=.01$, np $2=.006)$ but no statistically significant linear trend. There were statistically significant gender differences with the female students reporting more immediate correction of errors $(F(1,8)=14.33, p=$ .0001 , np $2=.006$ ) (boys $M=-.119$, girls $M=.064$ ) but no significant interaction between gender and level of expertise (see Figure 8). This was confirmed by a multivariate analysis of variance $(F(1,3185)=12.0, \mathrm{p}=.0001)$. There were statistically significant gender differences within the multivariate analysis in relation to the statements 'When I make a mistake I stop correct the wrong note and then carry on' $(F(1,3185)=11.77, \mathrm{p}=.001, \mathrm{np} 2=$ .004 ) (boys $M=4.79, S D=1.6$, girls $M=4.97, S D=1.4$ ); and 'When I make a mistake I carry on without correcting it' $(F(1,3185)=18.84, \mathrm{p}=.0001, \mathrm{np} 2=.006)($ boys $M=3.18$, $S D=1.6$, girls $M=2.9, S D=1.5$ ). 
Figure 8: Immediate correction of errors by gender and level of expertise

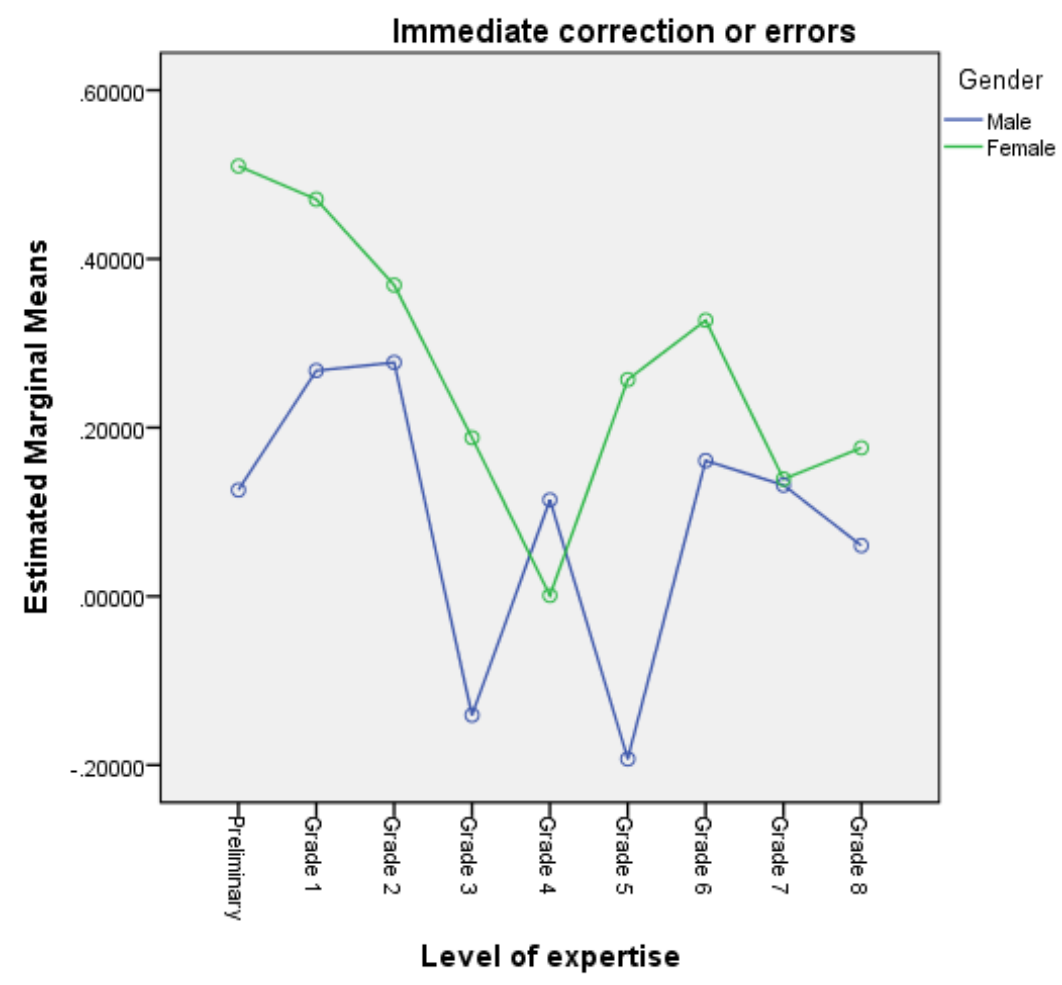

Are there gender differences in attitudes towards practising? Do these interact with level of expertise?

A Principal Components factor analysis was undertaken with varimax rotation on the variables related to attitudes towards practising. The details of this are set out in Hallam et al., 2012). The weightings for the variables were 'I like practising' -.743; 'On some days I don't want to practise' .623; and 'I find practising boring' .808. The factor focus is negative in terms of not enjoying practice. There was a significant effect of level of expertise on attitude to practice $(F(8,942)=3.8, p=.0001, n p 2=.031)$ and a statistically significant linear trend $(F(1,942)=12.5, p<.0001)$ indicating that as expertise increased enjoyment of practice decreased. There were no statistically significant gender differences or interactions between gender and level of expertise (see Figure 9). This was confirmed by a multivariate analysis of variance which also showed no statistically significant gender differences. 
Figure 9: Lack of commitment to and enjoyment of practice by gender and level of expertise

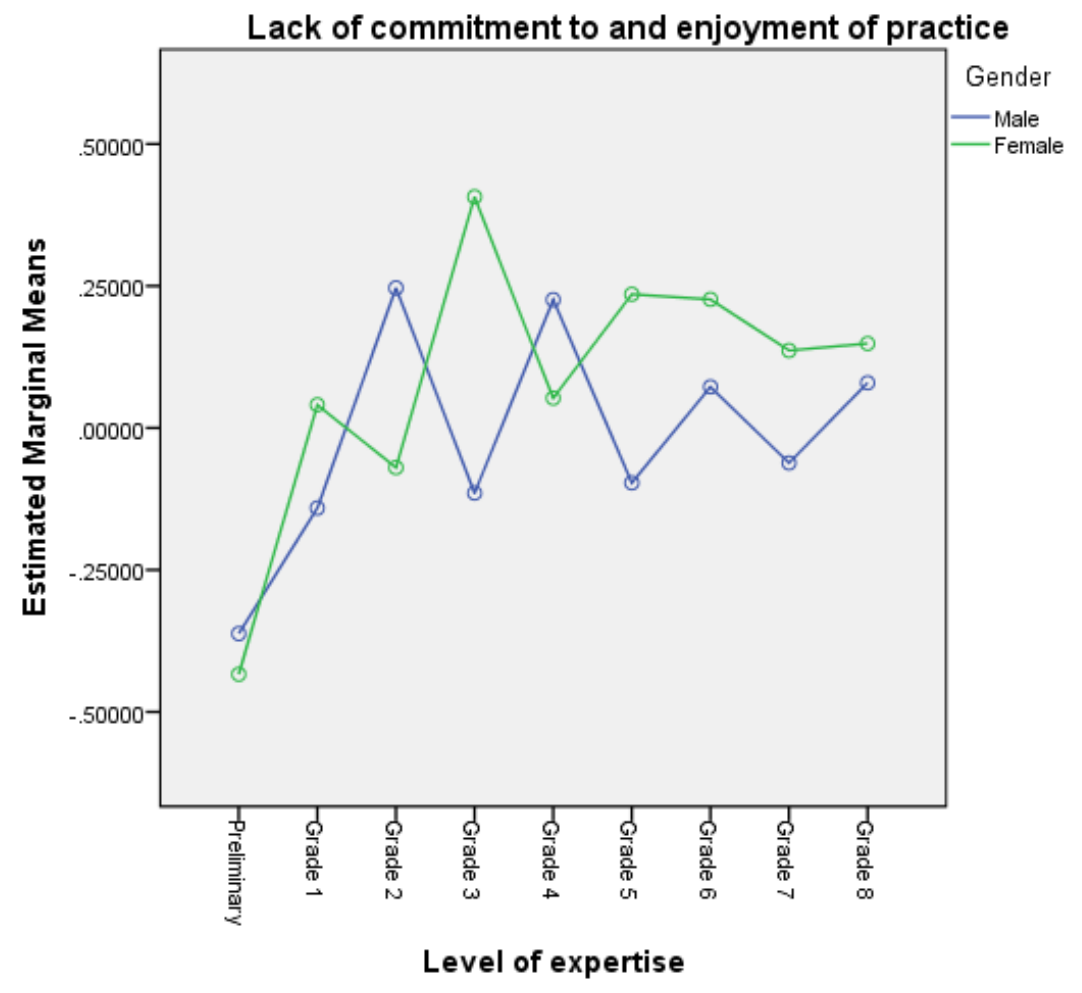

\section{Discussion}

There are limitations to this research in that it was based on self-report rather than observations or recordings of practice. Participants may not have reported their actual practice behaviours. As this limitation applies equally to the male and female participants the differences found are likely to reflect practice behaviours although it is possible that there are gender differences in approaches to responding to rating scales which may have distorted the findings. Notwithstanding these limitations the research has demonstrated some statistically significant gender differences in approaches to practice.

There were no differences in the overall time spent practising, although the boys reported practising on slightly more days than the girls. This is somewhat surprising as research on homework more generally has tended to show that girls spend more time undertaking homework than boys (Mau \& Lynn, 2000; Rogers \& Hallam, 2006; Wagner, Schober \& 
Spiel, 2008), although high attaining boys have been shown to do more homework than girls as they approach examinations (Rogers and Hallam, 2010). This may explain the findings given that the current sample includes boys from across the expertise continuum including those at high levels of expertise.

Of the seven factors identified, there were gender differences relating to three factors: adopting systematic practice strategies, adopting ineffective strategies, and concentration. The girls were more likely to adopt systematic practice strategies than boys including practising things slowly, gradually speeding up, adopting repetitive strategies when sections were difficult and marking things on the part to help them. The girls also reported correction of errors more frequently than the boys suggesting that their monitoring processes were more effective. However, the boys were less likely to adopt ineffective practising strategies particularly as beginners, for instance, going back to the beginning when making a mistake. The more systematic approach adopted by the girls is to some extent supported by the research on homework which suggests that girls manage the motivational, emotional and workspace elements of homework more successfully than boys (Xu, 2010), although Hong, Yun and Rowell (2009) found no difference in self-regulation strategies and Rogers and Hallam (2006) found that while high attaining boys did less homework than the girls they had more effective study strategies.

There were no statistically significant gender differences in relation to the factors organisation of practice, use of recordings and the metronome, the use of analytic strategies and attitudes towards practice. When individual items with high weightings on these factors were considered there were differences in organisation of practice relating to setting targets, making a list of what was to be practised, marking things on the part and starting practice 
with scales with girls more likely to undertake these activities. The boys were more likely to start their practice with warm up exercises. This difference might reflect instrument differences as warming up is particularly stressed in brass playing (Hallam, 2001a). Overall, the differences in individual statements relating to the organisation of practice reflect the findings relating to homework (Xu, 2010).

It is possible that the strategies adopted were influenced by the instruments played as boys formed the largest proportions playing brass instruments, percussion and drums supporting previous research on the gendering of musical instruments (Abeles, 2009; Abeles \& Porter, 1978; Cramer, Million, \& Perreault, 2002; Hallam, Rogers \& Creech, 2008; Harrison, 2000; Killian \& Satrom, 2011; Sheldon \& Price, 2005; Wych, 2012). Certainly, undertaking warm up exercises is generally more common in those playing brass instruments. We know relatively little about the way that those playing different instruments practice although there is some evidence of differences in the amount of practice undertaken by students in higher education with pianists and string players undertaking the most practice (Jørgensen, 2002). This is an area for further research.

In addition to the differences in the adoption of systematic practice strategies the boys also reported higher levels of concentration than the girls. While this may reflect actual gender differences in concentration it may indicate that the girls are more aware of when they are being distracted. Given the findings of $\mathrm{Xu}$ (2010) in relation to homework the latter is perhaps more likely.

The relationship between changes in practising and the development of expertise has been discussed extensively in Hallam et al. (2012). The findings for boys and girls reflect the 
broad trends reported there, although the patterns of change in some cases were less clear. In both studies, practice time was high in the intial stages of learning with a decrease after beginner level with a subsequent increase as repertoire becomes longer and more complex and there is the need for more technical work including scales and studies. Systematic practice for the whole sample showed an increase between beginner level and grade 1 with a subsequent decline to grade 3 followed by an increase to the higher levels of expertise. The gendered data reflected this although there was a considerable negative change for boys at the highest level of expertise. Why this might be requires further investigation. The factor relating to the use of ineffective strategies showed the overall decline found for the whole sample but there was a gender interaction as the boys in the beginner stages were less likely to return to the beginning of the piece if they made a mistake. Taken together these findings support the earlier literature indicating that overall as expertise develops practice tends to become more effective (Gruson, 1988; Hallam, 1997; McPherson and Renwick, 2001). In relation to listening to recordings and using the metronome and attitudes towards practice the pattern for the whole sample and the gendered analysis was similar. The remaining three factors organisation of practice, analytic strategies; and concentration showed no consistent patterns across the whole sample. This was reflected in the gendered analysis.

The findings suggest that, while the boys are more effective in their practice when they begin to play an instrument, they may not organise their practice as effectively as girls and may not adopt the most systematic practice strategies as their expertise develops. There is evidence that suggests that learners perceive that they are not taught how to practice by their teachers (Jørgensen, 2000).The current findings support the need for teachers to put more emphasis on teaching learners how to practice taking account of gender differences.

\section{References}


Abeles, H.F \& Porter, S.Y. (1978) 'The sex-stereotyping of musical instruments'. Journal of Research in Music Education, 26(2), 65-75.

Abeles, H.F. (2009). Are Musical Instrument Gender Associations Changing? Journal of Research in Music Education, 57(2), 127-139.

Abramo, J. M. (2011). Gender differences of popular music production in secondary schools. Journal of Research in Music Education, 59(1), 21-43.

Associated Board of the Royal Schools of Music (1994). Making music: The Associated Board Review of the teaching, learning and playing of musical instruments in the United Kingdom. London: ABRSM.

Baker, S., \& Cohen, B.M. (2008). From snuggling and snogging to sampling and scratching: girls' nonparticipation in community-based music activities, Youth Society, 39(3), 316-339.

Barry, N.H. (1992). 'The effects of practice strategies, individual differences in cognitive style, and gender upon technical accuracy and musicality of student instrumental performance'. Psychology of Music, 20, 112-123.

Chaffin, R., Imreh, G., Lemieux, A. F., \& Chen, C. (2003). "Seeing the big picture": Piano practice as expert problem solving. Music Perception, 20(4), 465-490.

Comber, C., Hargreaves, D.J. \& Colley, A. (1993). Girls, boys, and technology in music education, British Journal of Music Education. 10, 123-34.

Cramer, K.M., Million, E., \& Perreault, L.A. (2002). Perception of musicians: Gender stereotypes and social role theory. Psychology of Music, 30(2), 164-174.

Duke, R.A., Simmons, A.L. \& Cash, C.D. (2009) It's not how much, it's how. Characteristics of practice behaviour and retention of performance skills. Journal of Research in Music Education, 56, 310-321.

Ericsson, K.A., Krampe, R.T., \& Tesch-Romer, C. (1993). The role of deliberate practice in the acquisition of expert performance. Psychological Review, 100(3), 363-406.

Field, A. (2000). Discovering statistics using SPSS for Windows. London, thousand Oaks. New Dehli: Sage.

Gordon, E. (1986). Primary measures in music audiation (revised). Chicago, IL: GIA

Gruson, L.M. (1988). Rehearsal skill and musical competence: Does practice make perfect? In Sloboda, J.A. (Ed) Generative processes in music: The psychology of performance, improvisation, and composition. Oxford: Clarendon Press.

Green, L. (1997). Music, gender and education. NY: Cambridge University Press

Green, S.B. Salkind, N.J. \& Akey, T.M. (2000). Using SPSS for windows: Analysing and Understanding data (Second Edition) New Jersey: Prentice-Hall. 
Hallam, S. (1997). Approaches to instrumental music practice of experts and novices: Implications for Education, In: H. Jorgensen and A. C. Lehman (Eds), Does practice make perfect? Current theory and research on instrumental music practice. Norges musikkhogskole, Oslo.

Hallam, S. (1998).The predictors of achievement and drop out in instrumental tuition. Psychology of Music, 26(2), 116-132.

Hallam, S. (2001a). The development of meta-cognition in musicians: Implications for education. The British Journal of Music Education, 18(1), 27-39.

Hallam, S. (2004). Sex differences in the factors which predict musical attainment in school aged students, Bulletin of the Council for Research in Music Education, 161(16, ) 107-117.

Hallam, S. (2013). What predicts level of expertise attained, quality of performance, and future musical aspirations in young instrumental players? Psychology of Music, 41(3), 265289.

Hallam, S. Rinta, T. Varvarigou, M., Creech, A. Papageorgi, I., Gomes, T \& Lani, J. (2012). The development of practising strategies in young people. Psychology of Music, 40(5), 652680 .

Hallam, S., Rogers, L., \& Creech, A. (2008) Gender differences in musical instrument choice. International Journal of Music Education, 26(1), 7-19.

Hanley, B. (1998). Gender in secondary music education in British Columbia. British Journal of Music Education, 15(1), 51-6.

Hargreaves, D.J., Comber, C., \& Colley, A. (1995). Effects of age, gender and training on musical preferences of British secondary school students. Journal of Research in Music Education, 43(3), 242-250.

Hendricks, K.S. (2014). Changes in self-efficacy beliefs over time: Contextual influences of gender, rank-based placement, and social support in a competitive orchestra environment. Psychology of Music, 42(3), 347-365.

Harrison, A.C. (2000) Children's gender-typed preferences for musical instruments: An intervention study, Psychology of Music, 28(1), 81-97.

Hong, E., Yun, P. \& Rowell, L.L. (2009). Homework, self-regulation, grade, gender and achievement level differences. Learning and Individual Differences, 19(2), 269-276.

Joint Council for Qualifications (JCQ) (2014). GCSE and Entry Level Certificate Results Summer 2013. London: JCQ.

Jørgensen H (2000). Student learning in higher instrumental education: Who is responsible?' British Journal of Music Education, 17, 67-77.

Jørgensen, H. (2002). Instrumental performance expertise and amount of practice among instrumental students in a conservatoire. Music Education Research, 4, 105-119. 
Jørgensen, H. \& Hallam, S. (2016) Practicing. In S.Hallam, I. Cross \& M. Thaut (Eds) The Oxford Handbook of Music Psychology ( ${ }^{\text {nd }}$ Edition) pp 449-462) Oxford: Oxford University Press

Keiper., S., Sandene, B.A., Persky, H.R. \& Kuang, M. (2009). The Nation's report card: Arts 2008 - Music and visual arts. National Association of Educational Progress at Grade 8. Princeton, N.J. National Center for Education Statistics. ED505664.

Kelly, S.N. \& Van Weelden, K. (2014). Gender associations with world music instruments by secondary school music students from the USA. International Journal of Music Education, $32(4), 478-486$.

Killian, J.N. \& Satrom, S.L. (2011) The effect of demonstration gender on wind instrument preference of kindergarten, third-grade and fifth-grade students, Update: Applications of Research in Music Education, 29(2), 13-19.

Long, M., Hallam, S., Creech, A., Gaunt, H. \& Robertson, L. (2012). Do prior experience, gender or level of study influence music students' perspectives on master classes?

Psychology of Music, 40(6), 683-699.

Marshall, N. \& Shibazaki, K. (2012). Instrument, gender and musical style associations in young children. Psychology of Music, 40(4), 494-507.

Mau, W-C \& Lynn, R. (2000).Gender differences in homework and test scores in mathematics, reading and science at tenth and twelfth grade. Psychology, Evolution and Gender, 2(2), 119-125.

McPherson, G.E. \& O’Neill, S. (2010) Students' motivation to study music as compared to other school subjects: A comparison of eight countries. Research Studies in Music Education, $32(2), 101-137$.

McPherson, G. \& Renwick, J. (2001). Longitudinal study of self-regulation in children's music practice. Music Education Research, 3(1), 169-186.

Nielsen, S.G. (2004). Strategies and self-efficacy beliefs in instrumental and vocal individual practice. A study of students in higher music education. Psychology of Music, 32, 418-431.

Platz, F., Kopiez, R., Lehmann, A.C. \& Wolf, A. (2014). The influence of deliberate practice on musical achievement: a meta-analysis. Frontiers in Psychology, 5, 646.

Doi:10.3389/psyg.2014.00646

Ritchie, L., \& Williamon, A. (2011a). Measuring distinct types of musical self-efficacy. Psychology of Music, 39(3), 238-344.

Ritchie, L. \& Williamon, A. (2011b). Primary School Children's Self-Efficacy for Music Learning. Journal of Research in Music Education, 59(2), 146-161.

Rogers, L. \& Hallam, S. (2006) Gender differences in approaches to studying for GCSE among high achieving pupils. Educational Studies, 32(1),59-71. 
Rogers, L \& Hallam, S. (2010) Gender differences in perceptions of studying for the GCSE, International Journal of Inclusive Education, 14(8), 795-811.

Schatt, M.D. (2011). High School Instrumental Music Students' Attitudes and Beliefs Regarding Practice: An Application of Attribution Theory. Update: Applications of Research in Music Education, 29(2), 29-40.

Sheldon DA and Price HE (2005). Sex and Instrumentation distribution in an international cross-section of wind and percussion ensembles. Bulletin of the Council for Research in Music Education, 163, 43-51.

Sloboda, J. A., Davidson, J. W., Howe, M. J. A. and Moore, D. G. (1996). The role of practice in the development of performing musicians. British Journal of Psychology, 87, 287309.

Tabachnick, B.G. \& Fidell, L.S. (2001). Using multivariate statistics (Fourth Edition). Boston: allyn and Bacon, Pearson International.

Wagner, P., Schober, B. \& Spiel, C. (2008) Time students spend working at home for school. Learning and Instruction, 18(4), 309-320.

Wehr-Flowers, E. (2006). Differences between male and female students' confidence, anxiety and attitude toward learning jazz improvisation. Journal of Research in Music Education, 54, 337-349.

Welch, G., Papageorgi, I., Haddon, L., Creech, A., Morton, F., de Bezenac, C., \& Himonides, E. (2008). Musical genre and gender as factors in higher education learning in music. Research Papers in Education, 23, 203-217.

Wych, G.M.F. (2012) Gender and instrument associations, stereotypes an stratification: a literature review, Update: Applications of Research in Music Education, 30(2), 22-31.

Xu, J. (2010). Gender and homework management reported by African American students. Educational Psychology, 30(7), 755-770.

Zervoudakes, J. \& Tanur, J. (1994). Gender and musical instruments: Winds of change, Journal of Research in Music Education, 42, 58-67.

Zhukov, K. (2007). Student learning styles in advanced instrumental music lessons. Music Education Research, 9(1), 111-127.

Zhukov, K. (2008). Exploring the content of instrumental lessons and gender relations in Australian higher education, British Journal of Music Education. 25(2),159-176 


\section{Appendix}

\section{Research on instrumental practice}

We are conducting some research on instrumental practising. We would be very grateful if you would complete this questionnaire. It will take you about 10 minutes. Thank you for your time.

Name

Age

Main instrument

On average how many days a week do you practise?

On average, how much practice do you do on each day?

How long have you been learning your first instrument? years months

What is the most recent grade examination you have taken?

Please indicate in the table below how strongly you agree or disagree with the following statements. Please answer ONLY in relation to your main instrument.

\begin{tabular}{|l|l|l|l|l|l|l|l|}
\hline & $\begin{array}{l}\text { Very } \\
\text { strongly } \\
\text { agree }\end{array}$ & $\begin{array}{l}\text { Strongly } \\
\text { agree }\end{array}$ & Agree & Neutral & Disagree & $\begin{array}{l}\text { Strongly } \\
\text { disagree }\end{array}$ & $\begin{array}{l}\text { Very } \\
\text { strongly } \\
\text { disagree }\end{array}$ \\
\hline Practising strategies & & & & & & & \\
\hline $\begin{array}{l}\text { I try to get an overall idea of a piece } \\
\text { before I practise it }\end{array}$ & & & & & & & \\
\hline $\begin{array}{l}\text { When I practise I only play pieces } \\
\text { from beginning to end without } \\
\text { stopping }\end{array}$ & & & & & & & \\
\hline $\begin{array}{l}\text { I work things out just by looking at the } \\
\text { music and not playing }\end{array}$ & & & & & & & \\
\hline $\begin{array}{l}\text { I try to find out what a piece sounds } \\
\text { like before I begin to try to play it }\end{array}$ & & & & & & & \\
\hline $\begin{array}{l}\text { I work out where the difficult sections } \\
\text { are when I'm learning a piece of music }\end{array}$ & & & & & & & \\
\hline $\begin{array}{l}\text { I practise small sections of the pieces I } \\
\text { am learning }\end{array}$ & & & & & & & \\
\hline $\begin{array}{l}\text { When I make a mistake, I stop, correct } \\
\text { the wrong note and then carry on }\end{array}$ & & & & & & & \\
\hline $\begin{array}{l}\text { I try to get a recording of the piece that } \\
\text { I am learning so that I can listen to it }\end{array}$ & & & & & & & \\
\hline $\begin{array}{l}\text { I analyse the structure of a piece before } \\
\text { I learn to play it }\end{array}$ & & & & & & & \\
\hline I practise things slowly & & & & & & & \\
\hline I know when I have made a mistake & & & & & & & \\
\hline $\begin{array}{l}\text { When I make a mistake I practise the } \\
\text { section where I went wrong slowly }\end{array}$ & & & & & & & \\
\hline $\begin{array}{l}\text { When something is difficult I play it } \\
\text { over and over again }\end{array}$ & & & & & & \\
\hline
\end{tabular}




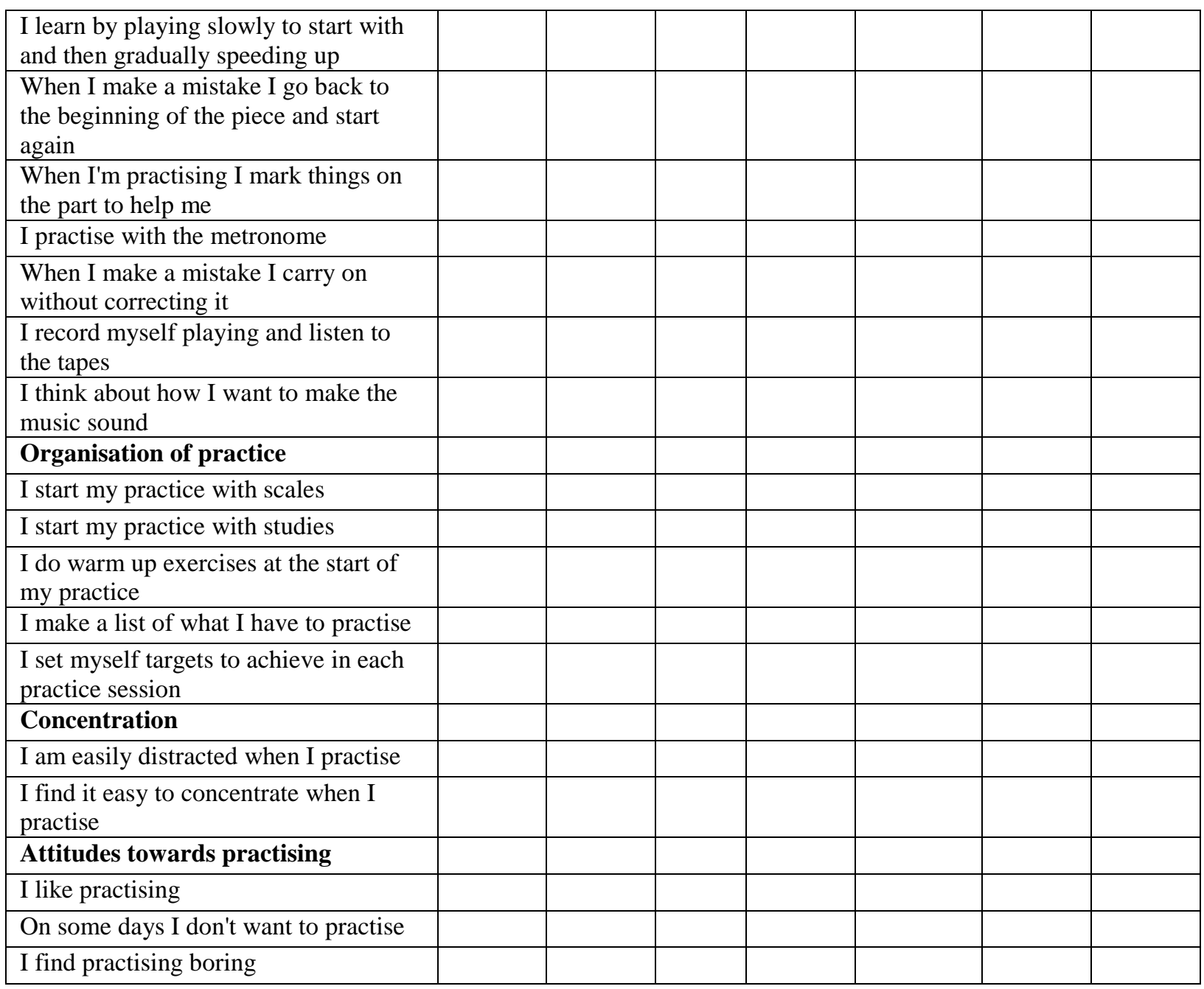

Thank you for completing this questionnaire 
